\title{
O problema da indeterminação dos espaços da cidadania: mídias digitais e identidades culturais na educação básica
}

Saulo Eduardo Ribeiro* Eliane Schlemmer**

Resumo

O artigo apresenta uma reflexão acerca do problema da indeterminação dos espaços de formação ou educação cidadã na contemporaneidade, marcada por novas formas de uso e apropriação dos espaços, não apenas físicos e analógicos, mas virtuais e digitais, ou melhor, híbridos. A dificuldade consiste justamente na delimitação desses espaços, haja vista o seu atravessamento por um espaço de natureza atópica e conectiva, o ciberespaço, sendo a internet e as mídias digitais a representação dessa "sucessão" à cidade física. Ante esse contexto, de territorialização, desterritorialização e reterritorialização, faz-se necessário repensar a questão das identidades culturais e sua importância para a questão da cidadania, haja vista que essas identidades não dependem mais apenas do território físico-geográfico para sua formação. O método utilizado consiste em revisão de literatura crítica, analítica e comparativa. Conclui-se que em uma sociedade mediatizada, pensar os meios de comunicação é imprescindível para pensarmos a cultura da participação nas escolas e nos processos formativos em geral.

Palavras-chave: mídias digitais, identidades culturais, educação básica, cidadania, culturas híbridas.

The problem of indetermination of citizenship spaces: digital media and cultural identities in basic education:

Abstract

The article presents a reflection on the problem of the indetermination of the spaces of formation or citizen education in contemporary times, marked by new forms of use and appropriation of the spaces, not only physical and analog, but virtual and digital or, rather, hybrids. The difficulty lies precisely in the delimitation of these spaces, given their crossing through a space of a topic and connective nature, cyberspace, with the Internet and digital medias being there presentation of this "succession" to the physical city. Against this background, of the territorialization, deterritorialization, and reterritorialization, it is necessary to rethink the question of cultural identities and their importance to the question of citizenship, since these identities no longer depend only on the physical-geographic territory for their formation. The method used consists of a literature review critical, analytical and comparative. It is concluded that in a mediatized society, thinking about the media is essential for thinking about the culture of participation in schools and in the formative processes in general.

Keywords: digital media, cultural identities, basic education, citizenship, hybrid cultures.

\section{Introdução}

Nesta análise teórica, levar-se-á em conta o surgimento das mídias, especialmente das mídias digitais, e o seu impacto no problemático projeto de produção, nas sociedades pós-industriais, de uma identidade cidadã relacionada ao sentimento de pertença. $\mathrm{O}$

\footnotetext{
* Doutor em Educação. E-mail: sloeduri@ gmail.com.

** Doutora em Informática na Educação. Professora Pesquisadora Titular do Programa de Pós-Graduação em Educação - UNISINOS. E-mail: elianeschlemmer@gmail.com.
} 
trabalho abordará o processo histórico de ressignificação do conceito e da prática cidadã, buscando pensar como uma educação/formação cidadã pode ser possível, no atual contexto, por meio do trabalho com as mídias e tecnologias digitais.

Pinsky e Bassanezi (2013) trazem em sua publicação estudos que abordam a dimensão histórica do conceito de cidadania. Cortina (2005), além dos aspectos históricos e teórico-conceituais, aborda os aspectos sociais e interculturais do conceito, especificamente sobre a problemática da geração de uma identidade intercultural, através do exercício de uma cidadania relacionada a um sentimento de pertença, no contexto das sociedades pós-industriais. A transformação do conceito será analisada tendo por referência as transformações do mundo na "sociedade em rede" (CASTELLS, 2013), especificamente dos impactos da internet na cultura da autonomia.

Canclini (2013) nos oferece a possibilidade de pensar uma identidade intercultural a partir da noção de cultura híbrida, que coloca o problema de como projetar formas de associação e cooperação em contextos de quebra e mescla das coleções simbólicas de arte culta e popular, e, por conseguinte, de desterritorialização dos processos simbólicos e de expansão de gêneros impuros. O processo de mundialização da cultura, em que os espaços se desterritorializam na medida em que são localizados pela presença de objetos mundializados, faz com que cada local revele o mundo em função da globalização dos lugares que, através das técnicas, unifica os espaços, fazendo com que o mundo esteja em todos os lugares (ORTIZ, 1996).

Em relação ao contexto escolar brasileiro, ele é aqui pensado sob a perspectiva da filosofia ou pensamento da libertação (FREIRE, 2005), da promoção da autonomia, da independência e da emancipação. Neste trabalho, a cidadania, a democracia e a liberdade são concebidas como práticas de participação coletivas, em espaços de convivência híbridos, multimodais, pervasivos e ubíquos (SCHLEMMER; BACKES; LA ROCCA, 2016). Essas práticas poderão ser desenvolvidas no contexto das instituições educativas brasileiras, na medida em que os diferentes espaços da cidade sejam transformados em espaços de aprendizagens, que venham a contribuir com a reestruturação dos conteúdos curriculares das escolas. 


\section{Aspectos teóricos e históricos do conceito de cidadania}

A cidadania, assim como a democracia, é um conceito histórico, e por não transcender a história é, também, um conceito móvel, modificando-se no espaço e no tempo. Por não ser transcendental, ele também não representa uma realidade absoluta. Sendo um conceito histórico, relativiza-se em condições concretas e materiais específicas, em problemas universalizáveis, mas não absolutos, universais, mas locais e globais ao mesmo tempo. Se a cidadania se materializa em certa forma de ser-no-mundo-com (o cidadão) e se o estatuto desse ser depende de uma relação de posse, então o cidadão é aquele que, ainda que formal e virtualmente, tem ou está em posse de direitos civis.

A democracia moderna pressupõe a cidadania, na medida em que o exercício desta é a expressão concreta do exercício daquela. Assim, o exercício da cidadania está relacionado não apenas a uma relação jurídico-formal de posse de certos direitos, mas a uma relação de uso real desses direitos, que se efetivam e se realizam, na medida em que sua virtualidade se atualiza, com a participação dos indivíduos na riqueza coletiva. Os usos reais são, tradicionalmente, resumidos ou reduzidos à participação nos destinos da cidade, por meio do exercício do direito de votar e ser votado. Esse exercício ou o seu uso decorre de uma posse formal ou virtual de direitos civis e políticos, que se atualiza de dois em dois anos, por intermédio da ação participativa de votar e ser votado.

Cidadania e democracia pressupõem participação, e ter direito à participação (liberdade de ação política) não garante aos indivíduos as condições materiais e de igualdade necessárias para pôr em obra tais direitos. Para que o exercício pleno dos direitos fundamentais e constitucionais dos indivíduos esteja garantido, é preciso que esses tenham acesso real a direitos sociais. Os direitos fundamentais são baseados na Declaração Universal dos Direitos Humanos, mas sua aplicação é relativa e não absoluta, pois é a atualização dos direitos humanos, conforme as particularidades culturais e históricas de um determinado contexto civilizacional. O exercício pleno da cidadania, no contexto de um Estado Nacional, consistiria no pleno exercício/uso dos direitos civis, políticos e sociais.

No entanto, a cidadania não pode ser reduzida aos seus aspectos jurídico-formais. Enquanto prática de liberdade, ela extrapola as formas de vida e de ação política institucionalizadas. Quando essas formas de civilidade institucional se mostram 
anacrônicas ou injustas, o exercício da cidadania e a prática cidadã se tornam insurgentes. A manifestação desobediente, sob a forma da civilidade e não da barbárie, se transforma em ação legítima e legalmente aceita.

A cidadania, por ser um conceito histórico que atravessou culturas e civilizações, está atrelada a diversos princípios éticos e políticos, sendo um deles o princípio da civilidade, que pressupõe a promoção e produção de uma sintonia através de um sentimento de pertença entre os indivíduos. Esse princípio tem uma pretensão de validade universal, pois teria a capacidade de contemplar a perspectiva de todos e transcender a esfera da subjetividade. As características de um princípio ético, além de expressarem a pretensão à universalidade, se constituem na imparcialidade, na humanidade, na consistência (entre juízo e ação) e na reversibilidade (pretende colocar o sujeito no lugar do outro).

No que diz respeito aos seus aspectos mais gerais, especificamente à Declaração Universal, um conceito mais amplo, mas ao mesmo tempo mais específico para esse tipo de cidadania, seria o de cidadania global ou planetária. Os fatores ou variáveis que vão influenciar na amplitude do conceito e na prática ou exercício da cidadania, em cada país, dizem respeito à abertura do estatuto de cidadão para imigrantes, ao grau de participação política de diferentes grupos ou setores da sociedade e aos direitos e proteção social.

\section{Da pré-história aos alicerces da cidadania moderna}

Essa cidadania moderna tem uma longa história, que inicia e encontra suas bases na antiguidade, com a cultura hebraica e seus profetas sociais, "que há quase trinta séculos falavam em cuidar dos despossuídos, proteger a viúva e o órfão, não pensar apenas em morar, comer e viver bem num mundo de pobreza extrema" (PINSKY; BASSANEZI, 2013, p. 10). Ele se amplia com o surgimento da cidade-estado greco-romana, onde a cidadania, cidade e Estado constituem um mesmo conceito. Isso se deve ao fato de a diversidade de povos e costumes já estar presente, desde a sua fundação. Civil ou cidadão é o ser humano livre, mas nem todos eram livres e a cidadania não era de acesso universal, mas somente para a nobreza ou para os patrícios. No cristianismo dos primeiros séculos, os princípios que caracterizariam a cidadania já estavam presentes nas redes associativas entre pessoas marginalizadas, que não eram assistidas pela administração romana e que 
lutavam de maneira organizada pela cidadania. No renascentismo, a questão da cidadania ressurge com a redescoberta do homem e com a recuperação da herança política clássica e reapropriação do direito romano.

No entanto, seus alicerces modernos são frutos das revoluções burguesas, especificamente: da Revolução Inglesa, com a separação dos poderes e o respeito aos direitos dos indivíduos; da Revolução Americana, com as liberdades individuais; e da Revolução Francesa, em que a liberdade é colocada como meta coletiva e não individual. A partir da passagem da figura do súdito e de seus deveres para a de cidadão e seus direitos, o conceito de cidadania passa por grandes transformações históricas, marcadas pela conquista dos direitos civis, no século XVIII, dos direitos políticos, no século XIX, e dos direitos sociais, no século XX. As revoluções burguesas também possibilitaram novas formas de Estado e de relações entre este, os indivíduos e a sociedade. Essas revoluções marcaram o desenvolvimento moderno da cidadania. A luta dos trabalhadores pelos direitos sociais, a luta das mulheres por igualdade, assim como das minorias religiosas, étnicas e nacionais, a luta por direitos humanos, tais como o direito à integridade física, passando pela questão da autodeterminação nacional, caracterizam esse processo de desenvolvimento e ampliação moderna do conceito de cidadania.

Se para os gregos a felicidade era o horizonte da ação ética e a meta da política, o mesmo não irá ocorrer para os modernos, onde a justiça passa a figurar como horizonte da ética e da política. A cidadania ressurge como conceito histórico, mas agora em função de um horizonte e de uma ação que têm a justiça social como o seu bem e fim último. Seguindo essa tradição, uma das críticas ao Estado de Bem-Estar Social consiste em afirmar que ele “gerou um cidadão dependente, ‘critiqueiro' e não crítico, passivo, apático e medíocre" (CORTINA, 2005, p. 64). De acordo com a filósofa, não é a solidariedade e o bem-estar (felicidade/prazer) que deve ser institucionalizado, mas um mínimo de justiça. A partir de então, a percepção de uma injustiça fará com que os indivíduos comecem a se mobilizar e a se identificar, por meio de um sentimento de indignação, que os levará a convergir em torno da promoção da justiça social.

A história da cidadania é a história de estabilizações em caixas-pretas e controvérsias, que explicitam suas limitações sociais, dentro de determinadas redes de significação constituídas por atores humanos e não humanos (LATOUR, 2005). O desenvolvimento das cidades inteligentes reacende o debate, instaurando novas 
controvérsias em torno dessas questões; afinal, como conciliar cidadania, que pressupõe autonomia e emancipação, com o propósito das cidades inteligentes, que parece pressupor justamente o contrário, automação e dependência? E qual a relação que os atores humanos e não humanos estabelecem com essa controversa, de que maneira se agenciam ou têm se agenciado na busca de novas estabilizações?

\section{O problema da cidadania nas sociedades pós-industriais}

Cortina (2005) busca analisar a cidadania sob seus aspectos sociais, econômicos, civis e interculturais. No que diz respeito aos aspectos sociais e civis, a cidadania toma realidade, ou atualiza e realiza sua virtualidade, a partir do momento em que os indivíduos se sentem motivados a trabalhar pela comunidade, pois sentem que, efetivamente, fazem parte dela, que pertencem àquela comunidade não por mera questão de formalidade jurídica, mas por uma identificação. A concepção de justiça social ganha grande relevância, pois não basta a formalidade jurídica para que um indivíduo se sinta pertencente a uma comunidade, é preciso que ele tenha os mesmos direitos e condições de igualdade na participação das riquezas coletivas dessa comunidade.

A civilidade, como virtude necessária para o exercício da cidadania, nasce e se produz através da sintonia entre a sociedade e cada um de seus membros (CORTINA, 2005). Essa sintonia se dá através do reconhecimento e da livre adesão, da produção de uma identidade relacionada ao sentimento de pertencimento. A oferta simbólica heterogênea crescente que é "renovada por una constante interacción de lo local con redes nacionales y transnacionales de comunicación" (CANCLINI, 2013, p. 265), a pluralidade e diversidade de modos e formas de expressão da vida social, cultural e política, dificultam a criação de uma identidade e de um espaço público onde essas diversidades possam circular, se articular e expressar, criando as condições e o espaço para a produção de um sentimento de pertença a uma comunidade caracterizada pela diversidade.

Esse contexto atualiza a problemática e a relevância do conceito de cidadania. Para Aristóteles (2002), a felicidade era a meta da política e só poderia se realizar na pólis. Com a diluição da cidade-estado, esse ideal e modo de vida filosófico passa a perder espaço para outros que pregam o retiro e distanciamento dos negócios e perturbações da cidade, tais como os epicuristas, os estóicos e os cínicos (EMPIRICO, 1997; EPICTETO, 
2006; EPICURO, 2002). Apesar disso, permanece a noção de comunidade, mas não mais centrada e dependente da ideia de pólis. A felicidade, horizonte da ação ética e meta da ação política segundo Aristóteles, é aquilo para o qual todo ser humano orienta sua ação, aquilo em que os homens convergem, e a cidade seria o espaço por excelência para a realização desse ideal, pois é nela que nos relacionamos uns com os outros, pelo exercício da virtude da civilidade e, por conseguinte, da cidadania.

Não há ética sem haver um outro. Se o horizonte da ética é a felicidade, então esta felicidade só se pode dar em uma relação com os outros, ela se produz na relação, e a cidade é o espaço privilegiado que possibilita a constante articulação-desarticulaçãorearticulação entre o eu e o outro. A ação ética do período clássico e helenístico tinha como horizonte a felicidade e o prazer, como realização do ideal de vida boa. No entanto, nem todos faziam ou se sentiam parte dos espaços públicos da cidade onde a "felicidade" poderia se realizar. Nesse sentido, surgem comunidades e escolas filosóficas divergentes, que irão enfatizar não um ideal de felicidade dependente da cidade, mas a busca de um prazer e uma felicidade que só dependem e podem ser buscados dentro de nós, e que consiste, basicamente, em ausência de dor física e de perturbação na alma. Ou seja, com a restrição do espaço e da esfera pública e ao estatuto de cidadão, constituídos por uma diminuta parcela da sociedade, os chamados "homens livres", era excluída uma grande parcela da sociedade da época. Além da comunidade política institucionalizada sob a forma da cidade-estado, havia e surgiam outras comunidades, cujas preocupações eram mais de ordem ética do que política.

Sócrates colocava a questão de como educar o cidadão para o exercício da virtude da civilidade na pólis, questão que se dissolve junto com a diluição da cidade-estado pela expansão do império macedônico por Alexandre Magno. Além disso, surgiu uma diversidade de escolas filosóficas, que se distanciam dos ideais socráticos e da filosofia platônica e aristotélica, e que tanto contribuíram para esse processo de diluição, quanto foram resultado dele. Após esse período, como visto, as questões da cidadania e da participação política passam a ser colocadas em outros termos. Se a expansão do império macedônico contribuiu para a diluição da cidade-estado e de sua já restrita e limitada esfera pública, a expansão urbana contemporânea tem contribuído para a diluição desses espaços públicos, ao mesmo tempo em que tem intensificado a hibridização cultural. Ao 
modo da fusão cultural, que misturou elementos do Oriente e do Ocidente, no período da expansão do império macedônico, a expansão urbana possibilitou que passássemos de

\begin{abstract}
sociedades dispersas em miles de comunidades campesinas con culturas tradicionales, locales y homogéneas, en algunas regiones con fuertes raíces indígenas, poco comunicadas con el resto de cada nación, a una oferta simbólica heterogénea, renovada por una constante interacción de lo local con redes nacionales y transnacionales de comunicación (CANCLINI, 2013, p. 265).
\end{abstract}

A expansão urbana exigirá, assim, uma expansão dos horizontes de participação política e cidadã. $O$ espaço público se dilui e passa a ser substituído por aquilo que Canclini chama de teleparticipação. O autor prossegue sustentando que, atrelado à expansão urbana, estão a serialização e o anonimato da produção que, somados às reestruturações da comunicação (agora tornada imaterial), modificam os vínculos entre público e privado. A vida do campo e a vida urbana também se hibridizam, na medida em que muitas mudanças culturais e gostos coincidem, graças às interações comerciais e à recepção de mídias eletrônico-digitais no meio rural, conectando o campo com as inovações da cidade.

Se na antiguidade a cidade e o espaço público são diluídos pela expansão do império macedônico, na contemporaneidade o espaço público se dilui na medida em que se fragmenta, pois, se antes era a cidade que não abarcava a todos os seus moradores, hoje são os cidadãos que não conseguem abarcar toda a cidade, buscando "en la intimidad doméstica, en encuentros confiables, formas selectivas de sociabilidade" (CANCLINI, 2013, p. 265). Os cidadãos habitam a cidade, na medida em que a isolam em um espaço próprio, sendo que "la esfera pública ya no es el lugar de participación racional desde el que se determina el orden social" (p. 266).

A fragmentação estrutural das cidades leva à fragmentação das mobilizações sociais, impossível de serem totalizadas sob uma única forma de participação ou bandeira, o que nos leva à necessidade de reorganização do espaço público. Desse modo, a falta de adesão dos cidadãos ao conjunto de uma comunidade não se deve, como se supõe, a um individualismo hedonista. O hedonismo como teoria, doutrina e movimento filosóficomoral, surge na Grécia, primeiro com Aristipo de Cirene, depois, de modo distinto, com Epicuro, e mais tardiamente é desenvolvido pelos utilitaristas modernos, tais como 
Bentham e Stuart Mill, tem muito pouco ou nada a ver com o que ocorre nas sociedades ditas pós-industriais.

A falta de adesão dos cidadãos e sua aderência a um modo de vida hedonista não se deve ao hedonismo ou a esse tipo de hedonismo filosófico, ou mesmo o de caráter consumista, mas às transformações políticas, sociais e econômicas que criaram as condições para o seu surgimento, tanto nas sociedades da antiguidade, quanto nas sociedades pós-industriais. Não é que falte um interesse pela coisa pública e pela participação de uma comunidade política, em busca de um bem coletivo e comum. Com a fragmentação da esfera pública, o interesse pela coisa pública, assim como a própria coisa pública, se fragmenta e não se deixa capturar por uma totalidade.

A atomização social de uma sociedade definida pela fragmentação e diversificação dos padrões identitários, as ações e participações políticas dos cidadãos "son de baja resonancia cuando se limitan a usar formas tradicionales de comunicación (orales, de producción artesanal o en textos escritos que circulan de mano en mano)" (CANCLINI, 2013, p. 267). Ao mesmo tempo em que há uma necessidade de gerar identidade relacionada ao sentimento de pertença, nas sociedades pós-industriais, há uma dificuldade inerente às transformações dessas sociedades, que desestruturam o espaço público, ao mesmo tempo em que expandem os espaços físicos da cidade, fragmentando e atomizando os espaços para o exercício da cidadania.

Apesar disso, essas transformações estruturais também são seguidas e se seguem de transformações tecnológicas, especialmente as relacionadas à comunicação, especificamente com o surgimento das redes e mídias massivas de comunicação. Nesse contexto, o poder de ação cidadã cresce, na medida em que atuam dentro e fora dessas redes, interferindo no funcionamento habitual de uma cidade, encontrando eco nos meios eletrônicos de informação, restituindo o sentido de urbano e, por conseguinte, o sentimento de pertença. Essas redes massivas de mídia e comunicação se convertem em meios de expressão amplificada de poderes locais, complementando os fragmentos através de atos conectivos (DI FELICE, 2017).

Aqui, a questão da importância do sentimento de pertença, para a produção de uma identidade social (CORTINA, 2005), vai ao encontro da questão da formação dos movimentos sociais, que "são desencadeados por emoções derivadas de algum evento significativo que ajuda os manifestantes a superar o medo e desafiar os poderes 
constituídos" (CASTELLS, 2013, p. 127). O medo, no entanto, “é superado pelo compartilhamento e pela identificação com outros num processo de ação comunicativa" (p. 127-128), que induzirá à ação e às mudanças coletivas. Nesse momento, a produção do entusiasmo se segue à mobilização societária, que "resulta da ação comunicativa que envolve a conexão entre redes de redes neurais dos cérebros humanos estimuladas por sinais de um ambiente comunicacional formado por redes de comunicação" (p. 128).

A mobilização emocional, que resulta no movimento social propriamente dito, é desencadeada, entre outras coisas, "pela indignação que a injustiça gritante provoca" (CASTELLS, 2013, p. 128). Isso vai ao encontro da reinvindicação, segundo a qual, a justiça social importa mais do que o bem-estar (CORTINA, 2005). No entanto, Cortina parece focar sua abordagem mais sob a perspectiva do Estado como promotor de uma justiça distributiva, que produziria o sentimento de pertença e civilidade entre os indivíduos de uma determinada sociedade. Isso levaria à produção de um senso de comunidade e da coesão social, por meio da livre adesão e participação dos indivíduos, no exercício da virtude moral da civilidade. Essa concepção de justiça passa a ser compartilhada por todos os membros de uma sociedade com Democracia Social. De acordo com Cortina, para isso é preciso descobrir o que os cidadãos consideram justo, pois é a partir da inserção dessa ideia nas instituições, que se pode gerar adesão, visto que as relações que estabelecemos, livremente, possuem mais força identificadora. Já, para Castells, são "as redes horizontais, multimodais, tanto na internet quanto no espaço urbano" que "criam companheirismo" e "é pelo companheirismo que as pessoas superam o medo e descobrem a esperança", favorecendo "a cooperação e a solidariedade, ao mesmo tempo que reduz a necessidade de liderança formal" (2013, p. 131-132).

Nessa perspectiva, a questão da identificação dos indivíduos a um princípio que os faça aderir a um movimento ou causa tem por referência, além da justiça social de Cortina, a cultura da autonomia em relação às instituições da sociedade. Se, de acordo com Cortina, Daniel Bell se referia ao problema do individualismo hedonista, Castells vai afirmar a necessidade de um novo conjunto de valores definidos como individuação e autonomia. A individuação, diferentemente do individualismo, enfatiza o indivíduo, mas adaptado à ação coletiva e a ideais comuns, e a autonomia consiste no processo de independência de instituições da sociedade para a realização desses projetos, por meio da constituição de redes sociais. Portanto, “o mundo real em nossa época é um mundo 
híbrido, não um mundo virtual nem um mundo segregado que separaria a conexão online da interação off-line" (CASTELLS, 2013, p. 137).

Nos espaços de fluxo, o sentimento de pertença flui e não dura para sempre, precisa e pode ser constantemente atualizado, e se atualiza quando uma injustiça é percebida como algo que já não pode mais ser ignorado por uma coletividade. A injustiça é o estopim, que desencadeia o sentimento de raiva e indignação, e o processo de ação comunicativa, através do compartilhamento e identificação com outras pessoas, supera o medo, produzindo entusiasmo e esperança.

\section{Culturas híbridas, multivíduo, interculturalidade cidadã e cidadania comunicativa}

A cidade e sua história constituem um cenário cada vez menos presente na formação das identidades coletivas (CANCLINI, 2013). As mídias constituem o sentido "público" da cidade mais do que a própria cidade, simulando a integração de um imaginário urbano desagregado. Nesse contexto, as questões coletivas ficam restritas aos interesses corporativos de cada grupo, restringindo, assim, o horizonte social das ações dos indivíduos desses coletivos. Outra forma de restrição do horizonte social das ações se dá mediante a remodelação do espaço público pela redução da participação social à prática do consumo. O cidadão reduzido à figura do contribuinte, cliente e consumidor: “o universo do consumo [...] como lugar privilegiado da cidadania” (ORTIZ, 1996, p. 122).

Com a reestruturação da cultura urbana, quando o espaço público tradicional cede espaço para as tecnologias eletrônicas, participar passa a consistir em "relacionarse con una 'democracia audiovisual', en la que lo real es producido por las imágenes gestadas en los medios" (CANCLINI, 2013, p. 269). A crescente expansão e desarticulação do urbano colocam em dúvida se os sistemas culturais encontram sua chave nas relações da população com determinado território e história, que prefiguraria os comportamentos dos grupos que constituem essa população. Os dispositivos de reprodução contribuíram para a desterritorialização dos sistemas culturais, ao hibridizar o culto e o popular, desestruturando as imagens e os contextos, assim como as referências semânticas e históricas que amaram os sentidos dessas imagens. 
La questión es entender como la dinâmica propia del desarrollo tecnológico remodela la sociedade [...] Hay sectores sociales con capitales culturales y disposiciones diversas para apropriárselas con sentidos diferentes: la descolección y la hibridación no son iguales para los adolescentes populares que van a los negócios públicos de videojuegos y para los de clase media y alta que los tienen en sus casas. Los sentidos de las tecnologías se construyen según los modos en que se institucionalizan y se socializan (CANCLINI, 2013, p. 287).

Essa reorganização também atinge a relação ou vínculo entre grupos sociais e sistemas simbólicos. Com os descolamentos contextuais e hibridizações não é mais possível vincular rigidamente as classes sociais com determinados estratos culturais. A perda da relação naturalizada da cultura com os territórios geográficos e sociais, assim como a relocalização territorial das velhas e novas produções simbólicas, é fruto da transnacionalização dos mercados simbólicos e das migrações. As economias cruzadas, os sistemas de significados que se interseccionam e as personalidades fragmentadas, que não podem mais ser identificadas pelo nascimento, família, estatuto profissional, por relações de amizade ou de propriedade, fazem cair por terra a noção tradicional de comunidade.

Tudo isso leva a uma reorganização cultural do poder e nos provoca a pensar sobre as consequências políticas de se passar de uma concepção vertical e bipolar do poder para outra concepção, descentrada e multideterminada. Canclini conclui que, ao perder sua relação exclusiva com o seu território, as culturas ganham em comunicação e conhecimento. Nesse sentido, "o espaço [...] transubstancia-se em elemento abstrato" (ORTIZ, 1996, p. 110). O indivíduo, nesse contexto, passa a ser reivindicado como uma pessoa internamente plural, um multivíduo, uma subjetividade não "unificável em uma totalidade ecológica" (CANEVACCI, 2012, p. 42).

Nesse sentido, apesar de ainda não termos uma sociedade intercultural, já temos muitos atores e identidades interculturais, identidades estas decorrentes desse processo de desterritorialização da cultura. Uma personalidade e uma identidade cultural fragmentada, um mosaico da diferença, onde sistemas de significado se interseccionam. As identidades são relações de uso. O seu si é apenas uma relação de uso consigo e com os outros, o si é a relação, e estas relações não são eternas, imutáveis e dadas desde sempre. Da mesma maneira que se fazem e acontecem, podem se desfazer e desaparecer. Como já dizia Heráclito, tudo flui e nada permanece. Assim, a cidadania só existe quando 
está em obra ou em uso, só existe como prática e enquanto está em prática, sem jamais se deixar capturar por uma forma cristalizada e estereotipada de cidadão.

Para assegurar um espaço público de convergência e exercício democrático da cidadania, a ética intercultural propõe o exercício do diálogo entre as culturas como possibilidade de uma interculturalidade cidadã (CORTINA, 2005). A cidadania ocorreria no exercício civilizado do diálogo, por meio do qual os indivíduos "esclareçam conjuntamente o que consideram irrenunciável para construir [...] uma convivência mais justa e mais feliz. Tendo em conta [...] que a compreensão de outros obtida por meio da convivência e do diálogo é indispensável para a autocompreensão" (p. 144). O desafio de uma ética e cidadania intercultural consiste em "conservar o melhor do universalismo e da sensibilidade diante do diferente [em algo que] os supere, sem desperdiçar a riqueza que uma e outra oferecem" (p. 146).

A abordagem contextualizada dessas questões está intimamente relacionada e imbrincada com a das tecnologias da informação e comunicação, assim como a das mídias digitais e seu papel na hibridização das culturas. A atualização do conceito de cidadania passa a se dar pela abordagem da noção de cultura digital e de desterritorialização dos espaços da cidadania, sob a forma do ciberespaço e da cibercidadania (LEMOS, 2004; LÉVY, 2001, 2007; ORTIZ, 2012). Outra abordagem é a que busca repensar a noção de cidadão em um mundo transnacionalizado, em que a comunicação é mediada por softwares, cujo modo de funcionamento desconhecemos e não controlamos (SILVEIRA, 2006). Se a mídia massiva constitui, hoje, o espaço público, e se a interculturalidade pressupõe diálogo, e se diálogo pressupõe comunicação, a comunicação, dimensionada pelas mídias, constitui as práticas políticas e a própria condição da cidadania.

Até que ponto a capacidade modeladora das práticas midiáticas incide sobre a condição cidadã? Se, conforme definem, a cidadania consiste no "ejercicio del derecho a tener derechos, esto es, como la posibilidad y capacidade de constituición de sujetos en el espacio público a través de prácticas articuladas en torno a las demandas y propuestas por derechos" (MONJE, 2009, p. 183), até que ponto as práticas midiáticas incidem sobre o processo de modelação dessas demandas e propostas? Como percebemos, nos estudos dos movimentos sociais, as mídias, tanto tradicional, mas principalmente as redes sociais digitais, exerceram um papel crucial no processo de formação desses movimentos (CASTELLS, 2013). 
A cidadania comunicativa consistiria no reconhecimento da capacidade de ser sujeito de direitos e de exercer esses direitos no terreno da comunicação pública. Nesse sentido, questiona-se: “cuál es el papel que cumplen los médios masivos de comunicación em la actual configuración del espacio público local y cuál es su compleja articulación con prácticas sociales y comunicativas desarrolladas en el espacio de la ciudad" (MONJE, 2009, p. 189)? Portanto, precisamos pensar os atores escolares como atores em comunicação e em fluxo de produção de sentido, em um contexto de ubiquidade territorial-digital. Não cabe estabelecer uma única forma de exercer a cidadania, mas de promover múltiplas cidadanias. Dessa maneira, essa promoção pode se dar mediante a promoção das vivências e das relações na cidade "com outras culturas comunicacionais, políticas, sociais, étnicas, regionais, classistas, religiosas e etárias que suscitam nas pessoas a procura de novidades, mudanças e fruições distintas da midiático/comerciais" (MALDONADO, 2017, p. 99).

\section{Considerações finais}

Toda virtude é uma disposição para o bem que se adquire com a prática de bons hábitos. A civilidade é uma virtude e um hábito que se adquire por meio da prática e do exercício da cidadania. Cidadania não é uma condição da qual se toma posse formal, isto é, por direito, mas uma condição que se realiza e se atualiza em uma relação ou situação de uso desses direitos. Assim, faz mais sentido falar em educação cidadã do que em educação para cidadania, pois, no primeiro caso, todos os sujeitos estão comprometidos com o ensino e com a aprendizagem, não é só o professor que ensina nem o aluno quem só aprende. Se a cidadania depende da virtude da civilidade, e se esta só pode ser adquirida ou desenvolvida com a prática desse hábito, então o papel do educador consistiria em criar situações práticas em que essa habilidade possa ser posta à prova e desenvolvida. $\mathrm{O}$ espaço da escola pode ser um começo, mas é necessário abranger outros espaços da cidade, assim como o ciberespaço ou os dois ao mesmo tempo.

Já dizia Paulo Freire (2005) que "ninguém liberta ninguém, ninguém se liberta sozinho"; a liberdade não pode ser concedida, não é algo que se possa ganhar ou conquistar passivamente. Apenas nos relacionamos com a liberdade por meio de práticas insurgentes, capazes de modificar os modos de participação institucionais. Uma potência 
destituinte. Liberdade não se concede, nem se conquista, liberdade se pratica e a cidadania é uma forma de praticar essa liberdade.

Nesse sentido, não se pode falar de cidadania na escola, dentro de uma concepção bancária, não se pode ensinar cidadania num padrão comunicacional transmissorreceptor, ou seja, não se pode educar para a cidadania dentro dessa lógica comunicacional binária. A educação na escola é cidadã e implica os educandos em um processo dialógico de fazer junto, que começa com a busca do conteúdo programático. Ou seja, uma educação cidadã é aquela em que a escola e os professores possibilitem o envolvimento de seus alunos, em todos os processos possíveis de participação, e que estimulem o desenvolvimento da autonomia, da colaboração, da união e da organização do educando. No espírito do que disse Castells, poderíamos considerar o espaço público da aprendizagem como aquele que é constituído pelo espaço escolar e urbano, somado às conexões das redes da internet.

Uma educação cidadã, mediada por uma prática docente que tenha por finalidade a promoção da autonomia e da emancipação do educando, e não a pura e simples instrução, é aquela que produza e promova as situações necessárias para o exercício e o desenvolvimento da cidadania. Assim, cria-se um ambiente escolar em sintonia com os processos de transformação tecnológica e organizacional da comunicação, levando-se em conta que essas transformações estão baseadas na autocomunicação e em redes horizontais de comunicação multidirecional e interativa. Em uma sociedade mediatizada, pensar os meios de comunicação é imprescindível para pensarmos a cultura da participação nas escolas e nos processos formativos em geral.

\section{Referências}

ARISTÓTELES. Ética a Nicômaco. São Paulo: EDIPRO, 2002.

CANCLINI, N. G. Culturas híbridas: estratégias para entrar e sair da modernidade. São Paulo: EDUSP, 2013.

CANEVACCI, M. Multivíduo conectivo: Gregory Bateson. Ciência e Cultura, v. 64, n. 1, p. 41-44, 2012.

CASTELLS, M. Redes de indignação e esperança: movimentos sociais na era da internet. Rio de Janeiro: Zahar, 2013.

CORTINA, A. Cidadãos do mundo: para uma teoria da cidadania. São Paulo: Loyola, 2005. 
DI FELICE, M. Net-ativismo - Da ação social para o ato conectivo. São Paulo: PAULUS, 2017.

EMPIRICO, S. Hipotiposes Pirrônicas Livro I. Disponível em: http://www.oquenosfazpensar.fil.puc-rio.br/index.php/oqnfp/article/view/130. Acesso em: 2 jul. 2019.

EPICTETO. A arte de viver. Rio de Janeiro: Sextante, 2006.

EPICURO. Carta sobre a felicidade. São Paulo: Editora UNESP, 2002.

FREIRE, P. Pedagogia do oprimido. Rio de Janeiro: Paz e Terra, 2005.

LATOUR, B. Reassembling the social: an introduction to actor-network-theory. New York: Oxford University Press Inc, 2005.

LEMOS, A. Cibercidades: um modelo de inteligência coletiva. In: Cibercidade: as cidades na cibercultura. Rio de Janeiro: Editora e-papers, 2004. p. 19-26.

LÉVY, P. Filosofia World: O Mercado; O ciberespaço; A consciência. Lisboa: Instituto Piaget, 2001.

LÉVY, P. Inteligencia Coletiva: por uma antropología del ciberespacio. São Paulo: Edições Loyola, 2007.

MALDONADO, A. E. Pensar os processos comunicacionais em recepção na conjuntura latino-americana de transformação civilizadora. In: Processualidades metodológicas: configurações transformadoras em comunicação. Florianópolis: Insular, 2017.

MONJE, D. I. Ciudadanía comunicativa: aproximaciones conceptuales y aportes metodológicos. In: Metodologías transformadoras: tejiendo la red en comunicación, educación, ciudadanía e integración em América Latina. Caracas: Fondo editorial CEPAO, 2009.

ORTIZ, R. Mundialização e Cultura. São Paulo: Brasiliense, 1996.

ORTIZ, R. R. Ciberciudadanías, multitud y resistencias. In: Ciberespacio y resistencias: Exploraciónen la cultura digital. Buenos Aires: Hekht Libros, 2012.

PINSKY, J.; BASSANEZI, C. História da cidadania. São Paulo: Contexto, 2013.

SCHLEMMER, E.; BACKES, L.; LA ROCCA, F. L'Espace de coexistence hybride, multimodal, pervasif et ubiquitaire: le quotidien de l'éducation à la citoyenneté. Educação Unisinos, v. 20, n. 3, p. 299-308, 2016.

SILVEIRA, S. A. Hackers, monopólios e instituições panópticas: elementos para uma teoria da cidadania digital. Líbero, n. 17, p. 73-81, 2006. 